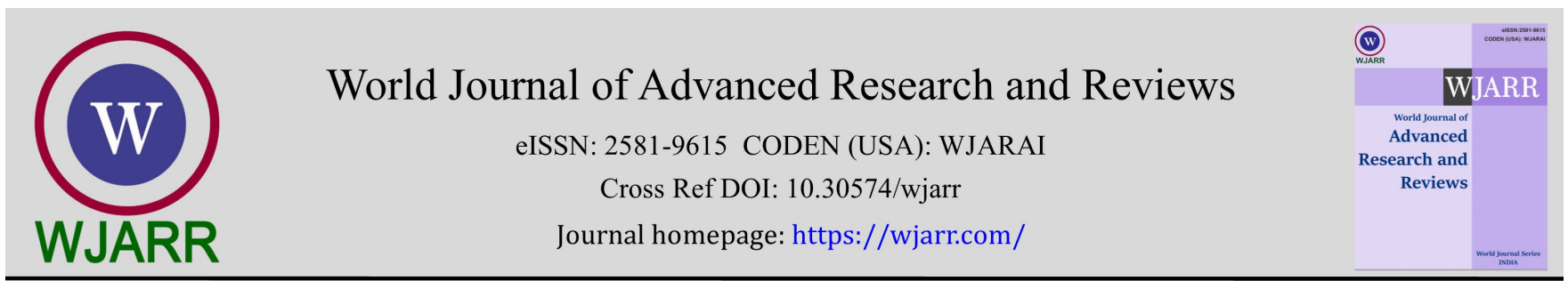

(RESEARCH ARTicle)

\title{
Statistical data for patients with breast cancer in the period from 2016 to 2019 in the eastern region of the republic of northern Macedonia
}

\author{
Jihe Zhu 1, Blagica Arsovska 1,2 and Kristina Kozovska 1,3,* \\ ${ }^{1}$ Faculty of Medical Sciences, University Goce Delchev, Shtip, Republic of Macedonia. \\ 2 Institute of Biology, Faculty of Natural Sciences and Mathematics, Skopje, Republic of Macedonia. \\ ${ }^{3}$ Medicine Faculty, St. Cyril and Methodius University of Skopje, Republic of Macedonia.
}

World Journal of Advanced Research and Reviews, 2021, 12(01), 182-185

Publication history: Received on 09 September 2021; revised on 06 October 2021; accepted on 08 October 2021

Article DOI: https://doi.org/10.30574/wjarr.2021.12.1.0507

\begin{abstract}
The term tumor growth, also referred to as neoplasia, is a new growth of tissue in the body. For this research was used analytical - descriptive research method. Processed data were taken from PHI CPH - Kochani, in the period from 2016 to 2019. The processed data shows that breast cancer is more common in women, most often from the age of 50-65. From the statistical research and obtained data on the number of diagnosed patients with breast cancer it can be noticed that out of the total 1532, 1053 women were aged 55-75, 452 women were aged 35-54 and 27 women were aged 2034. Most patients were registered in Kochani, total of 652. There were 15 patients aged 20-34 registered in Berovo, 10 in Kochani and 2 in Vinica. There were registered 226 patients aged 35-54 in Kochani, 95 in Vinica, 53 in Berovo, 45 in Makedonska Kamenica, 20 in Pehchevo and 13 in Delchevo. There were 416 patients aged 55-75+ registered in Kochani, 231 in Vinica, 193 in Berovo, 107 in Pehchevo, 70 in Delchevo and 36 in Makedonska Kamenica. Great attention should be paid to frequent examinations and to be repeated as often as possible during the year, because it is of great importance for the detection of the disease. If a malignant disease of the breast already appears in the fastest time, the patient should be accepted by a doctor who will lead the case (to remove the tumor and further therapy) because every life is worth improving and prolonging!
\end{abstract}

Keywords: Cancer; Breast; Screening; Tumor; Women

\section{Introduction}

The term tumor also referred to as neoplasia (neo = new and plasia = growth) represents a new growth of tissue in the body. Tumor growth in turn depending on the clinical behavior is divided into benign and malignant. Benign tumors have a limited growth capacity and do not invade adjacent tissues, so their complete surgical removal and cure is possible. They do not usually cause death. Malignant tumors grow invasively, with destruction of surrounding tissue and a tendency to spread and disperse, causing disease and death. Many factors contribute for the occurrence of breast cancer, such as the increase in the intake of foods rich with animal fats and lower intake of fruits and vegetables, the increase of the population and the increase of the number of the elderly population, as well as many other factors involved also genetic factors contribute to the occurrence of breast cancer. But here the key thing is the prevention of cancer, as well as timely detection and treatment. All this can be achieved by doing screening tests throughout the year, this is exactly what we want to raise awareness among women to do regular screening tests and breast self-examination. With self-examination about $90-98 \%$ of cases women find out the cause themselves. Every woman over the age of 20 should have a breast exam once a month. The etiology of breast cancer is an a complex nature, complex, multifactorial, which has not yet been defined in terms of function, breast development during life, changes during pregnancy, lactation, menstrual cycle, etc. Based on prospective and retrospective epidemiological studies that indicate a number

\footnotetext{
${ }^{*}$ Corresponding author: Kristina Kozovska

Faculty of Medical Sciences, University Goce Delchev, Shtip, Republic of Macedonia.

Copyright (C) 2021 Author(s) retain the copyright of this article. This article is published under the terms of the Creative Commons Attribution Liscense 4.0.
} 
of biological, reproductive and socioeconomic factors associated with an increased risk of breast cancer can be divided into three groups such as: Endocrine, Genetic factors with a family history and a history of benign breast disease, socioeconomic factors, exposure to relatively high doses of ionizing radiation.

Breast cancer in its early stages is usually asymptomatic. The patient usually notices a painless firmness in the breast area during self-examination or accidentally.We distinguish local, regional and systemic symptoms that occur in breast cancer. Local symptoms manifested by the presence of a tumor in the breast are palpable painless nodule, pain sensitive nipple, nipple sagging, nipple wound (erosion), sagging skin over the tumor, nipple secretion that may be serous, purulent, milky, and bloody, fixation of the breast to the pectoralis muscle or complete deformation of the breast. Regional symptoms occur as a consequence to the spread of the cancer to the regional lymph nodes. Lymph nodes in the armpit are most commonly metastasized, and a painless or painful tenderness in the armpit, painful tenderness, numbness, or even swelling of the arm due to a tumor in the armpit may occur. Systemic symptoms are manifested by the presence of distant metastases in the body and envy of their localization. General weakness and malaise, nausea, vomiting, neurological outbursts, bone pain, shortness of breath, choking, jaundice and others. People with early breast cancer can be offered the best chance of a cure. For breast cancer that has already spread to other organs, early detection of the disease allows early planning of appropriate treatment that may ultimately improve the patient's treatment outcomes. Time is of the essence, when it comes to diagnosing breast cancer.

For a definitive diagnosis of breast cancer, initial and additional diagnostic procedures should be performed first. Initial diagnostic procedures are a history of the disease and a physical examination by a doctor (specialist - oncologist). With the physical examination, the doctor can feel the tumor in the breast, to determine its localization, its size, consistency, mobility in relation to the skin, the substrate and the surrounding tissue. In addition to breast examination, regional lymph nodes should be examined, such as those in the armpit and nada and under the collarbones (axillary, supra, and infraclavicular lymph nodes). After the physical examination, if the doctor suspects the existence of breast cancer, further clinical examinations are continued. If the patient is having a breast self-examination, she should pay attention to: change in the shape and size of the breast, a lump or thickening, discharge from the nipple, redness, soreness, a swollen nodule or a gland in the armpit. Laboratory tests are performed, from which the initial examinations include: complete blood count, sedimentation, biochemical analysis of blood (liver tests, alkaline and acid phosphatase, calcium in the blood). Also a very important factor is the examination of tumor markers in the serum (MCA, CEA and CA15-3). Other clinical trials follow, such as: MAMMOGRAPHY (gold standard for detecting breast cancer !) , echotomographic examination of the breast (ultrasound) and biopsy. Also it is very important to emphasize that it is necessary to make additional examinations to determine the stage of the disease, ie radiographic examinations of the skeleton, chest and lungs. As well as scintigraphic examination of the skeleton, liver, and lymphoscintigraphy (a method used to detect metastases in the intramammary lymph nodes.)

Breast cancer is not just a local disease of the breast, but a systemic one that in the earliest stages has a tendency to metastasize. It is considered that at the time of diagnosis of the disease, when it is localized only in the breast, there are subclinical metastases, which can not be detected by existing diagnostic procedures. Therefore, the therapy of breast cancer itself is multidisciplinary, ie several oncological therapeutic modalities are included in the therapy. Which of these modalities will be applied depends on several factors such as the stage and grade of the disease, the patient's age, her general health and other factors. The main therapeutic modalities in breast cancer are surgery, radiotherapy, chemotherapy, hormone therapy, immunotherapy, targeted therapy.

The follow-up of the patients after the primary therapy is all in order to detect the possible relapse earlier and with the possible earlier started treatment to improve the quality of life. Curatively treated breast cancer patients are monitored every three months for the first three years and then every 6 months for the next 2 years and then once a year. Retrospective studies indicate that medical history and physical examination reveal 50 to $90 \%$ of relapses. [1-8]

\section{Material and methods}

As a working method was used analysis of statistical data for patients with breast cancer in the period from 2016 to 2019. The data are taken from PHI Center for Public Health - Kochani, RN. Macedonia.

The data are presented in tables and graphical presentation. 


\section{Results and discussion}

Treatment and education of breast cancer patients is essential. Patients with breast cancer need appropriate treatment, as well as their timely treatment and preventive education. In the following table the numbers of affected patients are significantly large and urgent education of the population is needed for malignant breast disease!

Table 1 Data from PHI, Center for Public Health - Kochani for breast cancer in the period 2016 - 2019 (for the following cities: Kochani, Vinica, Berovo, Makedonska Kamenica, Pehchevo and Delchevo)

\begin{tabular}{|c|c|c|c|c|}
\hline City & 20-34 years & 35-54 years & $55-75+$ years & Total \\
\hline Kochani & 10 & 226 & 416 & 652 \\
\hline Vinica & 2 & 95 & 231 & 328 \\
\hline Berovo & 15 & 53 & 193 & 261 \\
\hline M. Kamenica & 0 & 45 & 36 & 81 \\
\hline Pehchevo & 0 & 20 & 107 & 127 \\
\hline Delchevo & 0 & 13 & 70 & 83 \\
\hline
\end{tabular}

The results presented in table 1 show the number of total diagnosed patients in each municipality, divided into 3 age groups, for the period from 2016 to 2019. Most patients were registered in Kochani, total of 652, 328 in VInica, 261 in Berovo, 127 in Pehchevo, 83 in Delchevo and 81 in Makedonska Kamenica.

There were 15 patients aged 20-34 registered in Berovo, 10 in Kochani and 2 in Vinica. There were registered 226 patients aged 35-54 in Kochani, 95 in Vinica, 53 in Berovo, 45 in Makedonska Kamenica, 20 in Pehchevo and 13 in Delchevo.

There were 416 patients aged 55-75+ registered in Kochani, 231 in Vinica, 193 in Berovo, 107 in Pehchevo, 70 in Delchevo and 36 in Makedonska Kamenica.

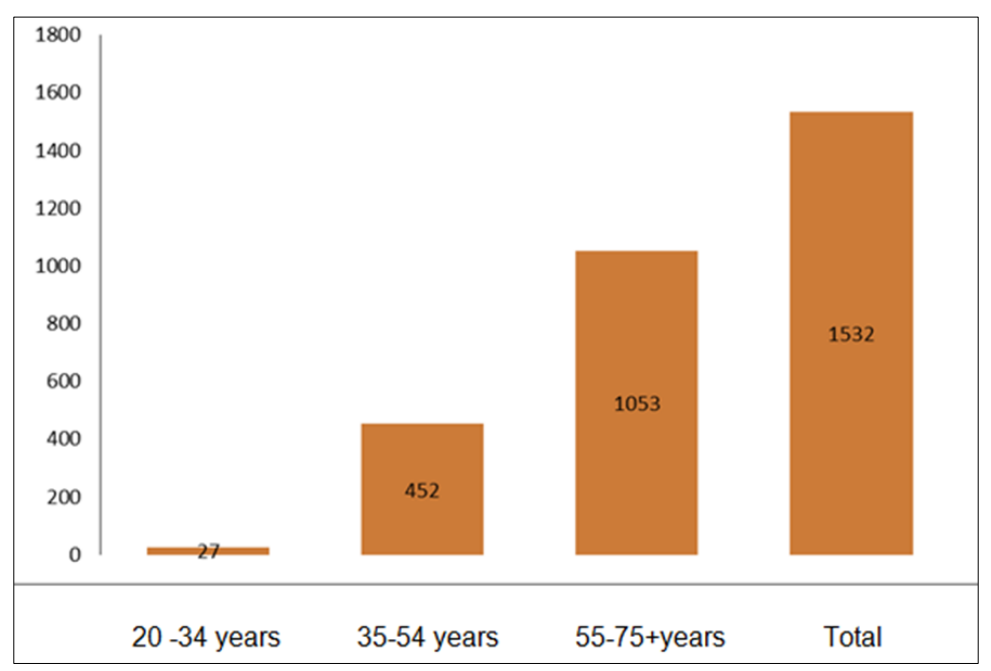

Figure1 Number of breast cancer patients by years from 2016-2019 and total in the Eastern Region

The processed data shown in figure 1 shows that breast cancer is more common in women aged 55-75 years. At that age, should be paid bigger attention to make regular examinations as well as regular self-examinations.

From the statistical research and obtained data on the number of diagnosed patients with breast cancer it can be noticed that out of the total 1532, 1053 women were aged 55-75, 452 women were aged 35-54 and 27 women were aged 2034 . 


\section{Conclusion}

From this research we can conclude that breast cancer is a very common malignant disease in women. Only with regular self-examinations and examination by a doctor as well as screening tests can contribute to the timely detection, improvement of life and healing of the woman. It is very important for every woman to be educated about this type of malignant disease so that it can be prevented in time.

Malignant diseases such as breast cancer can occur in any woman, especially in the middle age of 45-65 years. Great attention should be paid to frequent examinations and to be repeated as often as possible during the year, because it is of great importance for the detection of the disease. If a malignant disease of the breast already appears in the fastest time, the patient should be accepted by a doctor who will lead the case (to remove the tumor and further therapy) because every life is worth improving and prolonging!

\section{Compliance with ethical standards}

\section{Conflict of interest}

The author has declared that no competing interests exist.

\section{Statement of Informed Consent}

Written informed consent was obtained from the patient for their anonymized information to be published in this article.

\section{Source of funding}

This research received no specific grant from any funding agency in the public, commercial, or not-for-profit sectors.

\section{References}

[1] Acibadem Sistina. Symptoms of breast cancer. 2021.

[2] Todorov N. Guidelines for medical care for breast cancer. 2015.

[3] California Protons. Lekuvanje na dojka, cancer. 2021.

[4] Acibadem Sistina. Breast cancer. 2021.

[5] Stojanovski D. Principle of chemotherapy. 2019.

[6] Roche mk. Breast cancer. 2020.

[7] Institute of Public Health of the Republic of Macedonia; Mortality from malignant neoplasms in R. Macedonia. 2017.

[8] Zhu J. Oncology with radiotherapy - for students at the Faculty of Medical Sciences - Stip, general medicine seventh semester. 2019. 